\title{
AN ANALYSIS BETWEEN CHRONIC SUPPURATIVE OTITIS MEDIA AND CHRONIC BACTERIAL RHINOSINUSITIS
}

\author{
P. S. Maradesha ${ }^{1}$, Samatha K. J.2, M. K. Veenapani ${ }^{3}$ \\ ${ }^{1}$ Assistant Professor, Department of ENT, K. R. Hospital, Mysore. \\ ${ }^{2}$ Senior Resident, Department of ENT, K. R. Hospital, Mysore. \\ 3Professor and HOD, Department of ENT, K. R. Hospital, Mysore.
}

ABSTRACT

\section{AIM}

The objective of our study is to analyse the role of chronic bacterial rhinosinusitis as an important causative factor in CSO M with respect to aetiopathology, bacteriology, and radiology in adults and to establish the need of proper diagnostic evaluation of nose and paranasal sinuses before contemplating ear surgery.

\section{MATERIALS AND METHODS}

The study was conducted between December 2012 and February 2016 and focussed on 60 patients having CSOM (atticoantral and tubotympanic types - active stage) with chronic rhinosinusitis. Specific investigations included otomicroscopy, diagnostic nasal endoscopy, culture and sensitivity of aural and nasal swabs, HRCT temporal bone, and CT PNS were done for all cases.

\section{RESULTS}

In our study, the most common aerobic isolates were Staphylococcus aureus, Pseudomonas aeruginosa, and Streptococcus spp. Bilateral chronic suppurative otitis media with bilateral chronic bacterial rhinosinusitis was seen in majority of patients (33.3\%), among which tubotympanic type and maxillary sinusitis being the most common presentation.

\section{CONCLUSION}

Chronic bacterial rhinosinusitis is the most important causative factor in persistence of chronic suppurative otitis media tubotympanic and atticoantral. The objective assessment of all CSOM patients should be taken into consideration for comprehensive management of the disease.

\section{KEYWORDS}

Chronic Suppurative Otitis Media; Chronic Bacterial Rhinosinusitis; Tubotympanic Type, Atticoantral Type; Eustachian Tube.

HOW TO CITE THIS ARTICLE: Maradesha PS, Samatha KJ, Veenapani MK. An analysis between chronic suppurative otitis media and chronic bacterial rhinosinusitis. J. Evolution Med. Dent. Sci. 2016;5(67):4764-4768, DOI: 10.14260/jemds/2016/1086

\section{INTRODUCTION}

Chronic Suppurative Otitis media (CSOM) is the chronic inflammation of the middle ear (ME) cleft mucosa, which is characterised by irreversible changes in it with a history of ear discharge for more than 3 months through a permanent tympanic membrane defect.(1) The worldwide burden of chronic suppurative otitis media is 65-330 million people and approximately $60 \%$ suffer from clinically significant hearing impairment. $(2,3)$ According to the surveys conducted by WHO 2004 , the prevalence rate of chronic suppurative otitis media in India is $7.8 \%$ and frequency of hearing impairment (moderate hearing loss) is 77\% among the CSOM patients.

The most important pathological factors in CSOM are dysfunction of the Eustachian tube and bacterial infection. Poor living conditions, overcrowding, and poor hygiene and nutrition have been suggested for widespread of prevalence of CSOM in developing countries.

Financial or Other, Competing Interest: None.

Submission 30-06-2016, Peer Review 22-07-2016,

Acceptance 30-07-2016, Published 19-08-2016.

Corresponding Author:

Dr. P. S. Maradesha,

Assistant Professor,

Department of ENT,

K. R. Hospital,

Mysore.

E-mail:dr.mardesh@gmail.com

DOI: $10.14260 /$ jemds/2016/1086
Factors Responsible for Chronicity in CSOM

1. Chronic Eustachian tube dysfunction caused by:

- Chronic or recurrent nasal, paranasal sinuses, and throat infections.

- Partial or complete anatomic obstruction of Eustachian tube.

2. Persistent obstruction to aeration of the middle ear or mastoid spaces (this may be caused by scarring, thickened mucosa, polyps, granulation tissue, or tympanosclerosis).

3. Persistent perforation of the tympanic membrane.

4. Involvement of the middle ear with squamous metaplasia or other irreversible pathology.

5. Areas of sequestration or persistent osteomyelitis in the mastoid.

6. Constitutional factors such as allergy, debility, or altered defence mechanisms of the host.

7. Biofilm formation significantly increases the ability of the pathogen to evade both host defences and antibiotics.(4)

Of various aetiology for chronic suppurative otitis media, chronic bacterial rhinosinusitis acts as a focal sepsis in persistence of chronic otitis media in majority of cases in adults and such an interrelationship is supported by clinical experience and various literature.

The mucosa of the nose and paranasal sinuses are continuous with the mucosa of the middle ear cleft, hence pathologies in the sinonasal region can influence the normal milieu of the middle ear and mastoid. Chronic infections of the 
nose and Paranasal Sinuses (PNS) can involve the Eustachian tube leading to its dysfunction.(5) Patients who have CSOM secondary to chronic bacterial rhinosinusitis need to have both problems addressed.

Therefore, the present study was designed to analyse the patients having chronic suppurative otitis media with chronic bacterial rhinosinusitis with respect to aetiopathology, bacteriology, radiology, and thus establish the importance of adequate investigations in all cases for better surgical outcomes.

\section{MATERIALS AND METHODS}

The study of role of chronic bacterial rhinosinusitis in chronic suppurative otitis media was conducted in the Department of ENT, K.R. Hospital, Mysore, from December 2012 to February 2016. The institutional ethical committee approval was taken before starting the study.

\section{Inclusion Criteria}

1. Age - 18-60 years.

2. Sex - Both sex selected.

3. Patients having chronic suppurative otitis media of both tubotympanic (active mucosal) and atticoantral (active squamosal) types with chronic bacterial rhinosinusitis were chosen.

\section{Exclusion Criteria}

Patients with allergic rhinosinusitis, nasopharyngeal pathologies, congenital craniofacial anomalies, fungal otitis externa, traumatic tympanic membrane perforations, acute infections of nose and paranasal sinuses, sinonasal malignancies, associated medical comorbidities like diabetes mellitus, immunocompromised states, and diagnosed cases of ciliary dyskinesia. Patients with inactive mucosal and squamosal diseases were excluded.

A total of 60 patients of chronic suppurative otitis media of both tubotympanic and atticoantral types of active stage with chronic rhinosinusitis were selected from patients attending ENT OPD.

A questionnaire was filled for each patient. All patients were subjected to detailed examination, which included general physical examination, systemic examination, and careful examination of ear, nose, and throat. All cases were subjected for routine investigations, which included complete haemogram, blood sugar, serum creatinine, ECG, and chest $\mathrm{x}$ ray.

Otoscopic, microscopic examination of tympanic membrane findings, and tuning fork tests were performed.
Tympanic membrane was inspected for pathology like perforation, mucosal polyp, and cholesteatoma. Granulations in the attic or posterior margin of the tympanic membrane were looked for and studied. The middle ear mucosa through a perforation was evaluated for inflammatory changes.

The discharge from ear was collected using thin sterile cotton wool micro-swabs with full aseptic precautions using a microscope. This swab was immediately sent to the microbiology laboratory for culture and sensitivity. Pure Tone Audiometry (PTA) was done in all patients. Radiological imaging techniques like High Resolution Computed Tomography (HRCT) of temporal bones was done.

A rigid Diagnostic Nasal Endoscopy (DNE) was performed in all patients to evaluate the presence or absence of sinonasal diseases. During DNE, supratubal, and infratubal mucopurulent or mucoid discharge was collected using thin sterile cotton wool micro-swabs with full aseptic precautions. After DNE, CT scan of the paranasal sinuses were ordered in all patients to study the radiological extent of disease and to correlate this with pathology in the middle ear.

\section{RESULTS}

In our study, a total of 60 patients with chronic suppurative otitis media - both tubotympanic and atticoantral types with chronic bacterial rhinosinusitis were analysed. Following observations were made:

The age of the patients ranged from 18 to 60 years. Mean age was $33+11$ years. Out of 60 CSOM patients, 41 (68.3\%) were males and 19 (31.6\%) were females. 48 (80\%) belonged to low socioeconomic class. $10(16.6 \%)$ were from middle socioeconomic class and 2 (3.3\%) were from high socioeconomic class.

Right ear involvement was seen in $24(40 \%)$ patients, 17 (28.3\%) had left ear involvement, and 20 (33.3\%) had bilateral ear involvement.

In the study, out of 81 ears, 12 (44.4\%) and 15 (55.5\%) had atticoantral type of CSOM on right and left side respectively. Whereas, 32 (59.2\%) and 22 (40.7\%) had tubotympanic type of CSOM on right and left side respectively.

Out of 81 ears studied, 76 (93.8\%) ears had deafness and $41(53.9 \%)$ showed deafness in right ear and 35 (46.05\%) in left ear. Deafness was observed to be more in right ears.

$39(95.1 \%)$ ears on right side and $30(85.7 \%)$ ears on left side showed conductive hearing loss. 2 (4.8\%) and 5 (14.2\%) patients had mixed hearing loss on right and left side respectively. Majority of the patients showed mild conductive hearing loss i.e. between 26-40.

\begin{tabular}{|c|c|c|c|c|}
\hline \multirow{2}{*}{ Culture Isolates } & \multicolumn{2}{|c|}{ Aural swab (n=81) } & \multicolumn{2}{c|}{ Nasal swab (n=60) } \\
\cline { 2 - 5 } & Right (n=44) & Left (n=37) & Right (n=37) & Left (n=23) \\
\hline $\begin{array}{c}\text { Aerobes-Staphylococcus aureus, Pseudomonas } \\
\text { aeruginosa, streptococcus species }\end{array}$ & $27(61.36 \%)$ & $20(54 \%)$ & $23(62.16 \%)$ & $13(56.5 \%)$ \\
\hline $\begin{array}{c}\text { Mixed Organisms-Peptostreptococcus, Staphylococcus } \\
\text { aureus, Bacteroides, Streptococcus species }\end{array}$ & $17(38.63 \%)$ & $17(45.9 \%)$ & $14(37.8 \%)$ & $10(43.4 \%)$ \\
\hline \multicolumn{2}{|c|}{ Table 1: Distribution of CSOM Patients According to Their Aural Swab and Nasal Swab Culture Isolates (n=60) } \\
\hline
\end{tabular}

Bacterial isolates from majority of the patients revealed Staphylococcus aureus, Pseudomonas aeruginosa, and Streptococcus Species from aural swabs (58.02\%) and nasal swabs (60\%) indicating the bacteriological concordance between ear and sinus. 
In the patients with tubotympanic type of CSOM, medium central perforation was present in $11(25 \%)$ right ears and 11 (29.7\%) left ears, 7 (15.9\%) on right side and 8 (21.6\%) on left side had large central perforation, 13 (29.5\%) on right side and $7(18.9 \%)$ on left side had subtotal perforation involving all the quadrants and $1(2.2 \%)$ on right side had total perforation. Medialisation of handle of malleus was seen in 5 (7.46\%) ears on right side and $2(2.90 \%)$ ears on left side. Through the perforation when middle ear mucosa was studied, it was observed that 7 (15.9\%) ears on right side and $5(13.5 \%)$ ears on left side showed presence of congested polypoidal mucosa. In $1(2.2 \%)$ ear on right side, mucosal polyp was noted in the ear canal.

In the patients with atticoantral type of CSOM, $3(6.8 \%)$ had attic perforation on right side and 5 (13.5\%) had attic perforation on left side. $1(2.2 \%)$ patient had total perforation of tympanic membrane. 1 (2.2\%) had associated marginal granulations on right side and $1(2.7 \%)$ had granulation tissue polyp in the ear canal on left side.

In the present study, diagnostic nasal endoscopy was performed in all patients, following findings were observed: Deviated nasal septum was noted in $20(33.3 \%)$ patients on right side and 17 (28.3\%) patients on left side. Associated presence of spur was seen in $6(10 \%)$ patients on right side and $10(3.48 \%)$ patients on left side. Double middle turbinate on right side was seen in $2(3.3 \%)$ patients. $1(1.6 \%)$ patient on right side and $4(6.6 \%)$ patients on left side showed paradoxical middle turbinate.

\begin{tabular}{|c|c|c|}
\hline \multirow[t]{2}{*}{ HRCT Temporal Bone Findings } & $\begin{array}{c}\text { Right } \\
(n=44)\end{array}$ & $\begin{array}{c}\text { Left } \\
(n=37)\end{array}$ \\
\hline & No. (\%) & No. (\%) \\
\hline Hazy Mastoid Air Cell System & $12(27.2)$ & $9(24.3)$ \\
\hline Sclerotic Mastoid & $17(38.6)$ & $11(29.7)$ \\
\hline Soft Tissue Density in Epitympanum & $4(9)$ & $5(13.5)$ \\
\hline Soft Tissue Density in Attic & $4(9)$ & $5(13.5)$ \\
\hline Soft Tissue Density in Antrum & $10(22.7)$ & $10(27)$ \\
\hline $\begin{array}{c}\text { Soft Tissue Density in } \\
\text { mesotympanum }\end{array}$ & $5(11.3)$ & $8(21.6)$ \\
\hline Partial scutum erosion & $2(4.5)$ & $5(13.5)$ \\
\hline Total scutum erosion & $2(4.5)$ & $0(0.0)$ \\
\hline \multicolumn{3}{|c|}{$\begin{array}{l}\text { Table 2: Distribution of CSOM Patients According to } \\
\text { their HRCT Temporal Bone Findings }(n=60)\end{array}$} \\
\hline
\end{tabular}

\begin{tabular}{|c|c|c|}
\hline \multirow{2}{*}{ CT PNS } & Right & Left \\
\hline & No. (\%) & No. (\%) \\
\hline Deviated nasal septum & $20(33.3)$ & $17(28.3)$ \\
\hline $\begin{array}{c}\text { Total opacification of } \\
\text { Maxillary Sinus } \\
\end{array}$ & $3(5)$ & $2(3.3)$ \\
\hline $\begin{array}{l}\text { Total opacification of } \\
\text { Ostiomeatal Complex }\end{array}$ & $5(8.3)$ & $12(20)$ \\
\hline $\begin{array}{l}\text { Total opacification of Ethmoid } \\
\text { Sinus }\end{array}$ & $6(10)$ & $8(13.3)$ \\
\hline $\begin{array}{c}\text { Mucosal thickening in } \\
\text { Maxillary Sinus } \\
\end{array}$ & $20(33.3)$ & $29(48.3)$ \\
\hline $\begin{array}{l}\text { Mucosal thickening in } \\
\text { Ethmoidal Sinus }\end{array}$ & 25 (41.6) & $19(31.6)$ \\
\hline $\begin{array}{c}\text { Mucosal thickening in Frontal } \\
\text { Sinus }\end{array}$ & 13 (21.6) & $15(25)$ \\
\hline $\begin{array}{l}\text { Mucosal thickening in } \\
\text { Sphenoidal Sinus }\end{array}$ & $1(1.6)$ & $2(3.3)$ \\
\hline Fluid level in Maxillary Sinus & $23(38.3)$ & $29(48.3)$ \\
\hline Fluid level in Frontal Sinus & $5(8.3)$ & $8(13.3)$ \\
\hline $\begin{array}{c}\text { Fluid level in Sphenoidal } \\
\text { Sinus }\end{array}$ & $2(3.3)$ & $2(3.3)$ \\
\hline
\end{tabular}

In the present study, out of 60 CSOM patients, 25 (41.6\%) patients had bilateral chronic bacterial rhinosinusitis, 21 (35\%) had right chronic bacterial rhinosinusitis and 14 (23.3\%) patients had left-sided chronic bacterial rhinosinusitis.

\begin{tabular}{|c|c|c|c|}
\hline CSOM & $\begin{array}{c}\text { Chronic Bacterial } \\
\text { Rhinosinusitis }\end{array}$ & No. & \% \\
\hline $\begin{array}{c}\text { Bilateral } \\
\text { CSOM }\end{array}$ & $\begin{array}{c}\text { Bilateral Bacterial } \\
\text { Rhinosinusitis }\end{array}$ & 20 & 33.3 \\
\hline Right CSOM & $\begin{array}{c}\text { Right Bacterial } \\
\text { Rhinosinusitis }\end{array}$ & 20 & 33.3 \\
\hline Left CSOM & $\begin{array}{c}\text { Left Bacterial } \\
\text { Rhinosinusitis }\end{array}$ & 14 & 23.3 \\
\hline $\begin{array}{c}\text { Unilateral } \\
\text { CSOM }\end{array}$ & $\begin{array}{c}\text { Bilateral bacterial } \\
\text { rhinosinusitis }\end{array}$ & 6 & 10 \\
\hline $\begin{array}{c}\text { Table 4: Distribution of Patients with CSOM and Chronic } \\
\text { Bacterial Rhinosinusitis (n=60) }\end{array}$ \\
\hline \multicolumn{4}{|c}{}
\end{tabular}

\section{DISCUSSION}

Chronic Suppurative Otitis Media (CSOM) and sinusitis are the most well-known youth irresistible disease worldwide and is the most widely recognised reason for listening to debilitation in the creating scene despite the fact that it is rarely found in the created world.

Rhinosinusitis is an extremely common condition. The term rhinosinusitis is used interchangeably with sinusitis. Because the nasal mucosa is contiguous with that of the paranasal sinuses. Any inflammation of the sinuses is almost always accompanied by inflammation of the nasal cavity. Roughly, 1 in 200 viral upper respiratory tract occasions results in an auxiliary bacterial infection of the sinuses with the ethmoids and maxillary regarded the most regularly included. Interminable sinusitis might be an intricacy of rehashed bacterial infections, however, as a rule seems by all accounts to be a disease being portrayed by an unclear variation from the norm of the sinus mucosa. This inclines to constant infections. ${ }^{(6)}$

The upper respiratory tract including nose, paranasal sinuses, and Eustachian tube are lined by pseudostratified ciliated columnar epithelium. They also contain nonciliated columnar epithelium, basal cells, and goblet cells. The normal mucociliary clearance in which the anterior group of sinuses like frontal, maxillary, and anterior ethmoidal sinuses drain along the anterior and inferior part of pharyngeal end of Eustachian tube. The posterior group of sinuses including the posterior ethmoid and sphenoid sinuses drain posterior and superior to Eustachian tube. The mucus secreted by the paranasal sinuses are cleared by motility of the cilia, which are 50 to 200 per cell and they beat at the rate of 700 to 800 beats per minute moving at the rate of $1 \mathrm{~cm}$ per minute.(7)

Adam Politzer, an Australian physician, in 1867 first proposed the "ex vacuo" theory of otitis media. This theory postulates that chronic negative pressure secondary to Eustachian tube malfunction results in the development of transudate into the middle ear space.(8) Second aetiologic theory was first suggested by Brieger in 1914 and he proposed an inflammatory origin in otitis media.

Parsons noted over 15 years back that the centre ear is a paranasal sinus (Parsons DS, et al 1996) as the Eustachian tube acts in a comparative manner to the ostia of the paranasal sinuses. In both cases, the basic going before occasion is a viral upper respiratory infection. Wald ER, et al 2011 expressed that 
the mucosal swelling of the Eustachian tube and sinus ostia lead to (1) impedance of seepage of the discharges, which are created by the paranasal sinuses (2) a confusion of the weight connections between the depressions of the paranasal sinuses and the nose and (3) the advancement of negative weight inside of the paranasal sinuses, which supports desire of bodily fluid and microscopic organisms from the nasopharynx into the paranasal sinuses.(9)

Keeping in view, the importance of chronic bacterial rhinosinusitis in patients of CSOM; in our study, 60 cases of chronic suppurative otitis media were studied. The aetiopathology of the ear disease was analysed with coexisting chronic bacterial rhinosinusitis to find out direct correlation between them. In the present study, males 41 $(68.3 \%)$ were more commonly affected as compared to females 19 (31.6\%). Male-to-female ratio was 2.15:1. The predominant cause of the disease in males was due to their outdoor working habits exposing them to contamination and contagion. Patients belonging to low socioeconomic class were $48(80 \%)$. According to literature, the incidence of CSOM is higher in low socioeconomic class population due to poor hygienic living conditions and overcrowding.(1)

In the present study, 54 (66.6\%) ears had tubotympanic type and 27 (33.3\%) ears had atticoantral type of CSOM. Rightsided tubotympanic disease $32(59.2 \%)$ was more common than left, but left-sided atticoantral disease 15 (55.5\%) was more than the right. These findings were consistent with the findings of Saurabh V, Ashutosh N et al(10) who reported similar proportion of tubotympanic and atticoantral types in their study.

In the present study, out of 44 right and 37 left aural bacterial swab cultures, 27 (61.36\%) right ear swabs and 20 (54\%) left ear swabs revealed multiple pure aerobic microorganisms, most common being Staphylococcus aureus, Pseudomonas aeruginosa and Streptococcus spp.

In the present study, out of 60 patients, the culture report of nasal swabs revealed presence of same pathogenic isolates as that in the corresponding affected ears. The most common aerobic isolates were Staphylococcus aureus, Pseudomonas aeruginosa, and Streptococcus spp. Among anaerobes; Peptostreptococcus and Bacteroides were the commonest isolates. Chandra Bhan, Kartikeya Purohit(11) concluded that the commonest organism identified in their study was staphylococcus aureus in both safe and unsafe types of CSOM. In a study by Kiran Shah et al 2000 about unending sinusitis have found microbiological concordance between ear and sinus in $69 \%$ of patients where the predominant isolates was streptococcus pneumoniae. Therefore, we propose that ascending retrograde spread of these microorganisms to the middle ear via the Eustachian tube leads to CSOM. The presence of mucous on the Eustachian tube orifice may cause inflammatory oedema of the ET mucosa leading to its dysfunction.

In the present study, maxillary sinusitis (39.8\%) was present in majority of cases, which was followed by ethmoid sinusitis (21.8\%). Grote and Kuljpers detected maxillary sinusitis in $47 \%$ of 1252 paediatric cases with COME.(12)

A prospective study by Aditya M Yeolekar and K S. Sengupta.(13) at Department of ENT, Indira Gandhi Medical College, Nagpur, India, was conducted wherein distribution of sinonasal disease was studied in all 200 patients and concluded that sinonasal disease is the most common cause for the persistence of ear symptoms in chronic otitis media and supported by their improvement after treating the sinonasal pathology. They have emphasised that evaluation and management of sinuses is a must in all cases of chronic otitis media.

Gopalakrishnan and Kumar(14) also reported that in the adult population, sinusitis is the most important focal sepsis in case of persistent ear discharge in chronic otitis media active mucosal type of disease. A proper diagnostic nasal evaluation of all patients is necessary in comprehensive management of the ear disease. Fujita et al(15) reported in their study that $78 \%$ patients had abnormal sinuses and rhinosinusitis was present in $48 \%$ of cases of refractory otitis media and concluded that in cases of chronic otitis media refractory to treatment. The main focus of pathology/infection is in the paranasal sinuses.

Majority of investigators have revealed the important role of upper respiratory tract abnormalities as causative factors for Eustachian tube obstruction in the aetiopathogenesis of CSOM. Stammberger et al reported serious loss in Eustachian tube functions as a consequence of impaired function of nasal and paranasal sinuses.(16) In 1989, Bluestone and his colleagues(17) studied 40 patients of chronic otitis media and found Eustachian tube dysfunction to be the reason for the persistence of the disease. He concluded that diseases of the sinuses as the main cause for Eustachian tube dysfunction. M Miura and $\mathrm{H}$ Takashi.(18) studied the influence of upper respiratory infection including rhinosinusitis on tubal compliance in children and adolescents with chronic otitis media and they concluded that $72 \%$ of patients with refractory tubal compliance due to chronicity of upper respiratory infection including rhinosinusitis lead to persistence of otitis media.

\section{CONCLUSION}

In adults, chronic bacterial rhinosinusitis is the most important causative factor in case of persistent chronic suppurative otitis media. In our study:

1. Staphylococcus aureus is the predominant isolate revealing the microbiological concordance between ear and sinus.

2. Bilateral chronic suppurative otitis media with bilateral chronic bacterial rhinosinusitis was seen in majority of patients (33.3\%).

3. CSOM with chronic bacterial rhinosinusitis on the same side was a common phenomenon.

4. Tubotympanic type with maxillary sinusitis was the most common presentation.

5. Eustachian tube dysfunction resulted from chronic inflammation of sinuses.

On the basis of these results, we conclude that chronic bacterial rhinosinusitis plays an important role in persistence of chronic suppurative otitis media and hence the objective assessment of all CSOM patients with respect to bacteriology, radiology, and other supportive diagnostic tools should be taken into consideration for comprehensive management of the disease.

\section{REFERENCES}

1. Browning GG, Gleeson M, Burton MJ, et al. Scott-Brown's otolaryngology head and neck surgery. $7^{\text {th }}$ ed. Vol. 3. London: Hodder Arnold 2008:3395-434. 
2. Olatoke F, Ologe FE, Nwawolo CC, et al. The prevalence of hearing loss among school children with chronic suppurative otitis media in Nigeria, and its effect on academic performance. Ear Nose Throat J 2008;87(12):E19.

3. Acuin J. Chronic suppurative otitis media: burden of illness and management options. Geneva: World Health Organisation 2004.

4. Sritharan M, Sritharan V. Emerging problems in the management of infectious disease. The biofilms. Indian Journal of Medical Microbiology 2004;22(3):140-2.

5. Taneja MK. Contributing factors in otitis media. Indian Journal of Otology 1999;5(3):111-4.

6. AlHarbi JF. Sinusitis in a case of persistent chronic suppurative otitis media. International Journal of Healthcare Sciences 2016;3(2):314-7.

7. Stammberger. Functional endoscopic sinus surgery. 1992:105-13.

8. Ballenger JJ, Snow JB. Otorhinolaryngology, head and neck surgery. $15^{\text {th }}$ ed. Baltimore: Williams and Wilkins 1996:1003-9.

9. Parsons DS, Wald ER. Otitis media and sinusitis: similar diseases. Otolaryngol Clin North Am 1996;29(1):11-25.

10. Varshney S, Nangia A, Bist SS, et al. Ossicular chain status in chronic suppurative otitis media in adults. Indian Journal of Otolaryngology and Head and Neck Surgery 2010;62(4):421-6.
11. Bhan C, Purohit K, Purohit JP, et al. Clinical vs. bacteriological and mycological evaluation in chronic suppurative otitis media. International Journal of Contemporary Medical Research 2016;3(5):1443-7.

12. Grote JJ, Kuijpers W. Middle ear effusion and sinusitis. J Laryngol Otol 1980;94(2):177-83.

13. Yeolekar AM, Dasgupta KS. Otitis media: does the onus lie on sinonasal pathology? Indian J Otol 2011;17(1):8-11.

14. Gopalakrishnan S, Kumar S. A study of chronic suppurative otitis media active mucosal type with sinusitis as focal sepsis. Otol Online J ISSN 2250-0359, Vol 2(4).

15. Fujita A, Honjo I, Kurata K, et al. Refractory otitis media, organic abnormalities of Eustachian tube dysfunction and nasal sinusitis. American Journal of Otolaryngology 1993;14(3):187-90.

16. Stammberger $\mathrm{H}$. An endoscopic study of tubal function and the diseased ethmoid sinus. Arch Otorhinolaryngol 1986;243(4):254-9.

17. Bluestone CD. Assessment of Eustachian tube function. In: Jerger J, ed. Handbook of clinical impedance audiometry. New York: American Electromedics Corporation 1975:127-48.

18. Miura M, Takashi. Influence of URTI on tubal complaints and otitis media. Acta Otolaryngologica 1997;117(4): 574-7. 